\title{
Pesquisa em escala de demonstração do tratamento combinado de lixiviado
}

\section{Research on combined treatment of landfill leachate}

\author{
Ana Silvia Pereira Santos* \\ Doutora em Engenharia Civil - Tecnologia de Recursos Hídricos e Saneamento Ambiental pela COPPE/ \\ UFRJ. Pesquisadora do Departamento de Recursos Hídricos e Meio Ambiente - DRHIMA/UFRJ \\ Eduardo Pacheco Jordão \\ Doutor em Engenharia Civil. Professor Associado do Departamento de Recursos Hídricos e Meio Ambiente - DRHIMA/UFRJ \\ *Endereço para correspondência:Universidade Federal do Rio de Janeiro, Departamento de Recursos Hídricos e do Meio Ambiente - \\ Escola Politécnica. Centro de Tecnologia, Bloco D - Sala 204, Cidade Universitária - Rio de Janeiro, RJ - CEP: 21.949-900 - Brasil \\ - Tel.: +55 (21) 2562-7982 / +55 (21) 8168-7087/Fax: +55 (21) 2562-7994 - e-mail: anasilvia_santos@yahoo.com.br
}

Data de Entrada: 18/08/2011

Data de aprovaçăo: 26/01/2012

\section{RESUMO}

O objetivo do trabalho foi uma avaliação dos aspectos técnicos do tratamento combinado de lixiviado de aterro sanitário com esgoto doméstico. A pesquisa foi realizada com lixiviado dos aterros de Gramacho e Gericinó, em lagoas de estabilizaçáo para tratamento de esgoto doméstico gerado na Cidade Universitária da UFRJ. A diluição do lixiviado em esgoto doméstico foi realizada segundo taxas variando entre $0,2 \%$ e $2 \%(\mathrm{v} / \mathrm{v})$ em duas linhas operacionais: linha 01 - lagoa facultativa + lagoa de maturaçấo, com diluiçấo do lixiviado de Gramacho; linha 02 - lagoa aerada + lagoa de sedimentaçáo, com diluiçáo do lixiviado de Gericinó. A linha 01 apresentou resultados satisfatórios somente em uma das fases operacionais. Porém, a tecnologia que compóe a linha 02 demonstrou viabilidade para diluiçấo de até $0,5 \%(\mathrm{v} / \mathrm{v})$, apresentando neste caso, concentraçáo média efluente de DBO menor que $40 \mathrm{mg} / \mathrm{L}$ e de DQO menor que $100 \mathrm{mg} / \mathrm{L}$.

\section{ABSTRACT}

This work was aimed at evaluating the technical aspects of the combined treatment of landfill leachate with domestic wastewater. The research was conducted with dilution of landfill leachates from Gramacho and
Gericinó Landfills into two stabilization ponds in Rio de Janeiro. The experimental stabilization ponds received the leachate according to dilution rates ranging between $0.2 \%$ and $2 \%(\mathrm{v} / \mathrm{v})$ in two operational lines: Line 01 - facultative pond + maturation pond, operating with leachate from Gramacho landfill; Line 02 - aerated pond + sedimentation pond, operating with leachate from Gericinó landfill. Line 01 presented good results just in one of the phases, with $70 \%$ of average BOD removal and effluent average concentration less than $40 \mathrm{mg} / \mathrm{L}$. Line 02 , presented best results and in phases with up to $0.5 \%$ dilution, presented $\mathrm{BOD}$ effluent concentration less than $40 \mathrm{mg} / \mathrm{L}$ and $\mathrm{COD}$ effluent concentration under $100 \mathrm{mg} / \mathrm{L}$.

Palavras-chave: tratamento combinado, lixiviado de aterro sanitário, esgoto sanitário, lagoas de estabilizaçáo

Key words: combined treatment, leachate, wastewater, stabilization ponds

\section{INTRODUÇÁO}

O gerenciamento dos resíduos sólidos urbanos encontra sérios problemas de gestâo, desde o acondicionamento 
adequado por parte da populaçáo, passando pela coleta por parte dos órgãos responsáveis, até a correta disposição final.

Atualmente no Brasil, ainda se utiliza em larga escala o aterro sanitário para destinação final de resíduos sólidos, causando grandes impactos ambientais desde a sua construçáo até a sua operação e após o seu encerramento. Nos países desenvolvidos, políticas públicas e novas pesquisas têm incentivado cada vez mais a redução da utilização dos aterros.

No Japão, acredita-se que a utilização de tecnologias de incineração de resíduos seja mais ambientalmente correta e sustentável do que a sua disposição em aterros sanitários, em função de novas descobertas no tratamento de dioxinas liberadas no processo de queima (HARADA et al, 2007). Neste país, Segundo GIUSTI (2009), somente 3\% dos resíduos coletados em 2003 tiveram como destino final o aterro sanitário. Na Alemanha este valor correspondeu a 18\% em 2004 e na França, a 36\% em 2005. Ressalta-se que nesses países, grande parte dos resíduos foi incinerada, ou reciclada ou ainda destinada à compostagem.

Na Suécia, a utilizaçáo de aterros sanitários como disposição final de resíduos sólidos era usual. Porém, atualmente, devido à aplicação de impostos específicos para esta prática e um rápido crescimento das instalaçóes de incineraçấo de resíduos sólidos, a utilização de aterros sanitários se tornou menos significativa no país. De 2004 para 2005, a quantidade de resíduos aterrados na Suécia, diminuiu em 44,7\% (PERSSON et al, 2007).

$\mathrm{Na}$ Europa, desde 1999, as diretrizes para implantaçăo de aterro sanitário, constantes na CEC-1999/31/EC de 26 de abril de 1999, contêm requisitos para reduzir a quantidade de resíduos a serem depositados em aterros. Segundo as mesmas diretrizes, em 2016, os membros da Comunidade Européia não estarão permitidos a aterrarem mais de 35\% dos resíduos municipais biodegradáveis aterrados em 1995 (SCHARFF et al, 2007).

$\mathrm{Na}$ Holanda, de acordo com SCHARFF et al (2007), em 1993 aproximadamente 13 milhôes de toneladas de resíduos sólidos foram aterradas. Em 2005, este número foi reduzido a apenas 3 milhóes de toneladas. No mesmo período, o número de aterros em operaçáo foi reduzido de aproximadamente 80 unidades, para menos de 30 unidades.
Nos Estados Unidos, desde a promulgaçấo de novas orientaçốes e padrôes de emissão de gases, em 1996, ocorreram mudanças com relação à utilizaçâo de aterros sanitários como método de disposição final de resíduos sólidos. Segundo THORNELOE (2007), a porcentagem de resíduos sólidos aterrados em 1980 era $81 \%$ dos resíduos coletados. Em 2005, este índice foi reduzido para 54\%. O autor ainda afirma que em 1988 haviam aproximadamente 8000 aterros sanitários nos Estados Unidos e em 2005 este número era em torno de 1650 .

No Brasil, a maior parte dos resíduos sólidos que sofrem algum tipo de tratamento é disposta em aterros sanitários. Mas ainda a maior parte dos resíduos gerados é destinada a aterros controlados e lixóes. Segundo ABRELPE (2010), 61\% dos municípios brasileiros usam essas unidades como destino final de seus resíduos gerados. Já segundo o SNIS (2008), das 943 unidades de processamento de resíduos sólidos cadastradas no banco de dados de 2008, 18\% são aterros sanitários, 12,9\% são aterros controlados e $11,8 \%$ sấo lixôes. Ainda, somente $3,4 \%$ sâo unidades de compostagem e $2,2 \%$ sáo unidades de tratamento por incineraçấo. $\mathrm{O}$ restante está dividido em outras unidades de processamento como áreas de reciclagem de entulhos, áreas de triagem e transbordo, aterros de resíduos da construçáo civil, aterros industriais, unidades de tratamento por microondas ou autoclave, unidades de manejo de galhos e podas, valas específicas de resíduos de saúde, queima, dentre outros.

A ampla utilização de aterros sanitários no país traz uma discussão sobre seus subprodutos gerados: lixiviado e biogás. O tratamento deste último no Brasil é praticamente todo feito através da queima do metano $\left(\mathrm{CH}_{4}\right)$ e liberação do dióxido de carbono $\left(\mathrm{CO}_{2}\right)$. Já o tratamento de lixiviado é hoje apontado por técnicos da área como o principal problema associado aos aterros sanitários e de acordo com POVINELLI e SOUTO (2007), uma solução apropriada ainda nâo foi alcançada.

Uma aparente similaridade entre o lixiviado e o esgoto sanitário, apontada pelos técnicos no início das tentativas frustradas de tratamento do primeiro, levaram a erros consecutivos e a uma grande dificuldade de equacionamento do problema. Segundo ReCESA (2008), embora venham sendo adotados os processo de tratamento de esgotos domésticos aos lixiviados no Brasil, ainda não há dados concretos sobre a eficiência dos sistemas de tratamento empregados. 
Há ainda que se ressaltar, que segundo POVINELLI \& ALÉM SOBRINHO (PROSAB, 2009), as dificuldades encontradas pelos pesquisadores e engenheiros para tratar o lixiviado de aterros sanitários talvez se devam ao fato de ser um problema relativamente novo para a engenharia sanitária no Brasil. O início da implantação de aterros sanitários com impermeabilização de base se deu na década de 1970. Antes disso, o lixiviado era um líquido que infiltrava por toda a extensão da base dos aterros e, portanto se figurava como um problema de contaminaçāo do subsolo e das águas subterrâneas. Como náo era coletado e conduzido a algum local específico, não se pensava em um tratamento para o mesmo.

A composiçăo do lixiviado de aterros sanitários só passou a ser estudada e conhecida no princípio da década de 1970 (FLECK, 2003) e posteriormente se iniciaram os estudos para o tratamento desse efluente.

O lixiviado possui características que dificultam o seu gerenciamento e principalmente o seu tratamento biológico. Além de apresentarem elevadas concentraçôes de amônia, cloretos e de compostos recalcitrantes, existe a dificuldade de se estimar o seu volume, e ainda as suas características são bastante variáveis de um aterro para outro.

O tratamento biológico do lixiviado tem se mostrado pouco eficiente e os tratamentos físico-químicos, normalmente apresentam custos bastante elevados, operação complexa e geraçáo de lodo químico de difícil gestão.

Já a evaporação do lixiviado pode ser considerada como uma tecnologia emergente em todo o mundo, principalmente quando utiliza equipamentos unitários instalados em cada unidade de saída de biogás do aterro. Sistemas únicos que recebem todo o lixiviado produzido no aterro sáo utilizados, porém apresentam grandes extensóes de tubulaçáo e ainda uma elevada dificuldade operacional.

Atualmente, apresenta-se como uma solução conveniente para o tratamento do lixiviado de aterros sanitários, o seu tratamento combinado em unidades existentes de tratamento de esgoto doméstico. No tratamento combinado, é importante a avaliaçáo da compatibilidade do processo convencional de tratamento já implantado com as características do lixiviado produzido. Essa soluçâo é uma das alternativas adotadas em vários países como forma de reduzir os custos de operaçáo dos aterros, inclusive no Brasil.

Os insucessos obtidos no Brasil e no mundo todo apontam para a necessidade de se repensar as estratégias até agora adotadas, buscando processos adequados para o tratamento do lixiviado e que possam ser aplicados dentro da realidade brasileira (POVINELLI \& ALÉM SOBRINHO, PROSAB 2009). Considerando os problemas no tratamento por processos biológicos e físico-químicos convencionais, é necessária a busca de alternativas de tratamentos eficientes dentro de um padrăo de sustentabilidade técnica e econômica.

Dessa maneira, uma pesquisa em escala de demonstração foi realizada, com o objetivo de analisar aspectos técnicos do tratamento combinado de lixiviado e esgoto doméstico, levando-se em consideraçáo tanto o grau de complexidade operacional como a adequaçáo dos efluentes à legislação ambiental vigente para lançamento em corpos d'água.

\section{METODOLOGIA}

A pesquisa de tratamento combinado em escala de demonstraçáo (500 habitantes) foi desenvolvida nas lagoas facultativa, de maturação, aerada e de sedimentaçáo do Centro Experimental de Saneamento Ambiental da Universidade Federal do Rio de Janeiro CESA/UFRJ, em um período de quatro meses para cada linha de tratamento.

Foram utilizadas duas linhas de tratamento, conforme descritas a seguir e representadas na Figura 1:

- Linha 01: lagoa facultativa (LF) + lagoa de maturaçáo (LM) + diluição lixiviado Gramacho;

- Linha 02: lagoa aerada (LA) + lagoa de sedimentaçáo (LS) + diluição lixiviado Gericinó.

Ainda na Figura 1, pode-se observar os tanques de 1000 Litros que foram instalados nas proximidades das lagoas experimentais para armazenamento dos lixiviados provenientes dos aterros de Gramacho e de Gericinó, localizados no município do Rio de Janeiro. O abastecimento era realizado semanalmente por meio de caminhão pipa e a diluiçáo do lixiviado nas lagoas era realizada por meio de bomba dosadora, 


\section{Artigos técnicos}

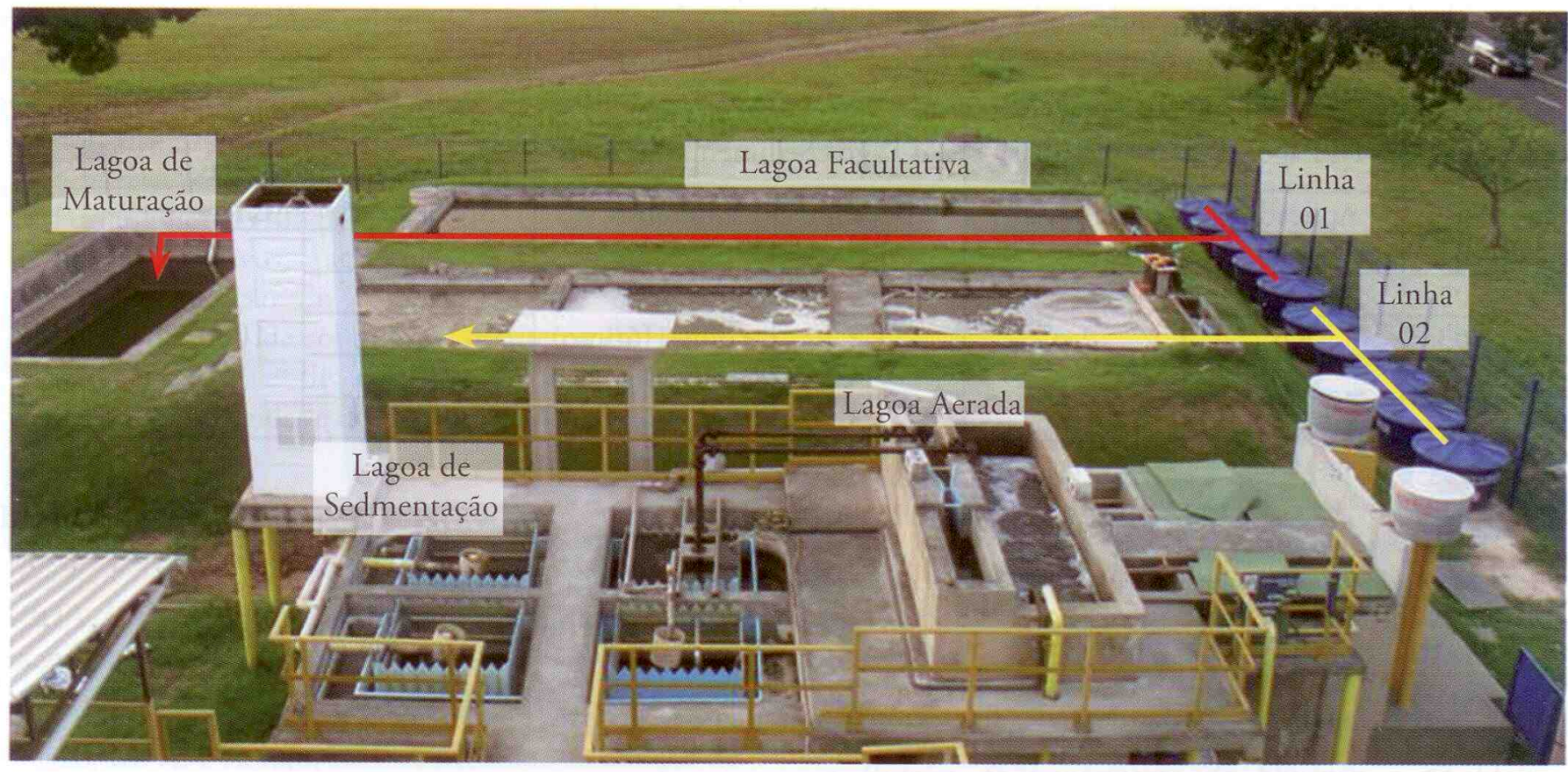

Figura 1 - Aparato experimental em funcionamento

em regime constante.

É importante ressaltar que as lagoas facultativa e de maturação já haviam sido operadas por FONSECA (2005) para o tratamento de esgoto doméstico sem a adição de lixiviado e seus resultados foram utilizados para comparação de desempenho do tratamento combinado. De maneira análoga, o mesmo pode-se relatar em relação às lagoas aerada e de sedimentação que haviam sido operadas por MATOS (2005). Ambas as pesquisas referidas foram desenvolvidas entre os anos de 2003 e 2005.
No presente trabalho, as linhas de tratamento 01 e 02 foram avaliadas em 05 diferentes fases operacionais, com características distintas, sendo cada uma delas operada por aproximadamente 04 meses.

Nas Tabelas 1 e 2 pode-se observar as principais características de operação das lagoas das linhas 01 e 02 de tratamento, respectivamente, para cada umas das 05 fases. Na Tabela 3 estão apresentadas as características de vazão e fator de diluiçáo, utilizados em cada fase operacional da pesquisa.

Tabela 1 - Resumo das condiçóes operacionais para a linha 01

\begin{tabular}{|c|c|c|c|c|c|c|}
\hline \multirow[t]{2}{*}{ Fase } & \multicolumn{2}{|c|}{ Td Lagoa Facultativa (dias) } & \multicolumn{2}{|c|}{ Td Lagoa Maturaçáo (dias) } & \multicolumn{2}{|c|}{$\begin{array}{c}\text { COS Lagoa Facultativa } \\
(\mathrm{kgDBO} / \text { ha.dia })\end{array}$} \\
\hline & Aplicado* & Literatura** & Aplicado* & Literatura** $^{* *}$ & Aplicado*** & Literatura** \\
\hline 01 & 6,6 & \multirow{5}{*}{$15-45$} & 3,2 & \multirow{5}{*}{$>3 \quad-7$ (ótimo) } & 313 & \multirow{5}{*}{$\begin{array}{l}100-350 \\
\text { (regiōes } \\
\text { tropicais) }\end{array}$} \\
\hline 02 & 6,6 & & 3,2 & & 221 & \\
\hline 03 & 16,5 & & 8,1 & & 95 & \\
\hline 04 & 16,5 & & 8,1 & & 95 & \\
\hline 05 & 16,5 & & 8,1 & & 95 & \\
\hline
\end{tabular}

Obs.: Td $\rightarrow$ Tempo de detençāo hidráulica

$\mathrm{COS} \rightarrow$ Carga Orgânica Superficial

* Valor aplicado no período

** Faixa recomendada pela bibliografia (JORDĀO \& PESSOA, 2009) para esgoto doméstico

*** Valor aplicado em função da concentração afluente média de DBO no período e da vazāo imposta 
Tabela 2 - Resumo das condiçóes operacionais para a linha 02

\begin{tabular}{|c|c|c|c|c|c|c|}
\hline \multirow{2}{*}{ Fase } & \multicolumn{2}{|c|}{ Td Lagoa Aerada (dias) } & \multicolumn{2}{|c|}{ Td Lagoa Sedimentação (dias) } & \multicolumn{2}{|c|}{$\begin{array}{c}\text { COS Lagoa Aerada } \\
(\mathrm{kgDBO} / \text { ha.dia })\end{array}$} \\
\hline & Aplicado* & Literatura** $^{* *}$ & Aplicado* & Literatura** & Aplicado*** & Literatura** $^{* *}$ \\
\hline 01 & 4,8 & \multirow{5}{*}{$2-4$} & 1,5 & \multirow{5}{*}{$<2-1$ (ótimo) } & 557 & \multirow{5}{*}{$1000-3000$} \\
\hline 02 & 4,8 & & 1,5 & & 574 & \\
\hline 03 & 3,6 & & 1,2 & & 774 & \\
\hline 04 & 7,1 & & 2,3 & & 304 & \\
\hline 05 & 7,1 & & 2,3 & & 286 & \\
\hline
\end{tabular}

Obs.: Td $\rightarrow$ Tempo de detençáo hidráulica

$\mathrm{COS} \rightarrow$ Carga Orgânica Superficial

* Valor aplicado no período

** Faixa recomendada pela bibliografia (JORDÃO \& PESSOA, 2009) para esgoto doméstico

*** Valor aplicado em funçáo da concentraçáo afluente média de DBO no período e da vazáo imposta

Tabela 3 - Vazôes de lixiviado e esgoto doméstico e respectivas porcentagens de diluiçáo

\begin{tabular}{|c|c|c|c|c|c|c|c|c|}
\hline \multirow{3}{*}{ Fase } & \multicolumn{4}{|c|}{ Linha Operacional 01 } & \multicolumn{4}{c|}{ Linha Operacional 02 } \\
\cline { 2 - 9 } & Vazão afluente & $\begin{array}{c}\text { Vazáo } \\
\text { Gramacho }\end{array}$ & Diluição & Vazáo afluente & $\begin{array}{c}\text { Vazáo } \\
\text { Gericinó }\end{array}$ & Diluição \\
\cline { 2 - 8 } & $(\mathrm{L} / \mathrm{s})$ & $(\mathrm{L} / \mathrm{h})$ & $(\mathrm{L} / \mathrm{h})$ & $(\%)$ & $(\mathrm{L} / \mathrm{s})$ & $(\mathrm{L} / \mathrm{h})$ & $(\mathrm{L} / \mathrm{h})$ & $(\%)$ \\
\hline 01 & 0,10 & 360 & 7,20 & 2,0 & 0,15 & 540 & 10,80 & 2,0 \\
\hline 02 & 0,10 & 360 & 1,80 & 0,5 & 0,15 & 540 & 2,70 & 0,5 \\
\hline 03 & 0,04 & 144 & 0,72 & 0,5 & 0,20 & 720 & 3,60 & 0,5 \\
\hline 04 & 0,04 & 144 & 0,72 & 0,5 & 0,10 & 360 & 1,80 & 0,5 \\
\hline 05 & 0,04 & 144 & variável & $\pm 0,2$ & 0,10 & 360 & variável & $\pm 0,2$ \\
\hline
\end{tabular}

Obs.: Linha $01 \longrightarrow$ Lagoa Facultativa + Lagoa de Maturaçấo

Linha $02 \rightarrow$ Lagoa Aerada + Lagoa de Sedimentaçáo

Ressalta-se que na Tabela 3, os dados de vazáo de lixiviado estão apresentados em $\mathrm{L} / \mathrm{h}$ e os dados de vazão afluente estão apresentados $\mathrm{em} \mathrm{L/s} \mathrm{e} \mathrm{L} / \mathrm{h}$, para facilitar o entendimento. Ainda, a vazáo de lixiviado da fase 05 , por estar condicionada à sua concentraçáo de amônia, foi variável e apresentou uma diluiçáo de aproximadamente $0,2 \%$ para ambas as linhas operacionais.

Para desenvolvimento desse trabalho, foram avaliados os parâmetros $\mathrm{DBO}, \mathrm{DQO}$ e N-Amoniacal, que foram analisados de acordo com o que preconiza a $20^{\text {a }}$ ediçáo do Standard Methods for the Examination of Water and Wastewater.

\section{RESULTADOS}

As 05 fases operacionais das duas linhas de tratamento combinado foram analisadas em relaçáo às respectivas estatísticas descritivas das concentraçôes afluentes e efluentes e das eficiências de remoção.

Para a linha 01 , as estatísticas descritivas dos parâmetros DQO, DBO e $\mathrm{N}$-amoniacal, para as fases operacionais de 01 a 05 podem ser observadas nas Tabelas 4, 5, 6, 7 e 8 respectivamente. Para a linha 02, esses valores são encontrados nas Tabelas 9, 10, 11, 12 e 13.

É importante ressaltar que os valores de média, mínimo, máximo e desvio padráo sáo referentes a um determinado número de dados (diferentes datas de coleta) para cada amostra. Se o número de dados de duas diferentes amostras de uma mesma fase for equivalente, náo necessariamente os valores correspondem à mesma data de coleta. Dessa forma alguma discrepância pode ser encontrada ao se comparar valores de média, mínimo, máximo e desvio padrăo de distintas amostras de uma mesma fase. 
Tabela 4 - Estatísticas descritivas da fase operacional 01 (Linha 01)

\begin{tabular}{|c|c|c|c|c|c|c|c|}
\hline Fase & Parâmetro & Amostra & $\begin{array}{c}\text { No } \\
\text { Dados }\end{array}$ & $\begin{array}{l}\text { Média } \\
(\mathrm{mg} / \mathrm{L})\end{array}$ & $\begin{array}{c}\text { Mínimo } \\
(\mathrm{mg} / \mathrm{L})\end{array}$ & $\begin{array}{c}\text { Máximo } \\
(\mathrm{mg} / \mathrm{L})\end{array}$ & $\begin{array}{l}\text { Desvio } \\
\text { Padrấo }\end{array}$ \\
\hline \multirow{12}{*}{1} & \multirow{4}{*}{ DQO } & Esgoto bruto & 15 & 493 & 115 & 1728 & 445 \\
\hline & & Lixiviado bruto & 15 & 3279 & 2088 & 3836 & 431 \\
\hline & & Diluição (afluente) & 12 & 315 & 200 & 518 & 97 \\
\hline & & Efluente & 12 & 173 & 75 & 253 & 63 \\
\hline & \multirow{4}{*}{$\mathrm{DBO}$} & Esgoto bruto & 15 & 238 & 37 & 654 & 176 \\
\hline & & Lixiviado bruto & 15 & 412 & 118 & 857 & 178 \\
\hline & & Diluição (afluente) & 11 & 181 & 119 & 298 & 55 \\
\hline & & Efluente & 9 & 75 & 48 & 96 & 18 \\
\hline & \multirow{4}{*}{$\mathrm{N}$-amoniacal } & Esgoto bruto & 7 & 44 & 17 & 101 & 27 \\
\hline & & Lixiviado bruto & 7 & 2385 & 530 & 3090 & 845 \\
\hline & & Diluição (afluente) & 7 & 99 & 32 & 219 & 61 \\
\hline & & Efluente & 7 & 50 & 21 & 111 & 31 \\
\hline
\end{tabular}

Tabela 5 - Estatísticas descritivas da fase operacional 02 (Linha 01)

\begin{tabular}{|c|c|c|c|c|c|c|c|}
\hline Fase & Parâmetro & Amostra & $\begin{array}{c}\text { No } \\
\text { Dados }\end{array}$ & $\begin{array}{l}\text { Média } \\
\text { (mg/L) }\end{array}$ & $\begin{array}{c}\text { Mínimo } \\
(\mathrm{mg} / \mathrm{L})\end{array}$ & $\begin{array}{c}\text { Máximo } \\
(\mathrm{mg} / \mathrm{L})\end{array}$ & $\begin{array}{l}\text { Desvio } \\
\text { Padráo }\end{array}$ \\
\hline \multirow{12}{*}{2} & \multirow{4}{*}{ DQO } & Esgoto bruto & 15 & 235 & 140 & 419 & 76 \\
\hline & & Lixiviado bruto & 16 & 3208 & 1950 & 4255 & 601 \\
\hline & & Diluição (afluente) & 13 & 236 & 105 & 387 & 80 \\
\hline & & Efluente & 13 & 141 & 32 & 256 & 78 \\
\hline & \multirow{4}{*}{$\mathrm{DBO}$} & Esgoto bruto & 15 & 127 & 70 & 239 & 41 \\
\hline & & Lixiviado bruto & 12 & 336 & 137 & 663 & 155 \\
\hline & & Diluição (afluente) & 12 & 128 & 71 & 199 & 46 \\
\hline & & Efluente & 11 & 58 & 16 & 147 & 33 \\
\hline & \multirow{4}{*}{$\mathrm{N}$-amoniacal } & Esgoto bruto & 6 & 47 & 26 & 98 & 27 \\
\hline & & Lixiviado bruto & 6 & 1211 & 228 & 3565 & 1222 \\
\hline & & Diluição (afluente) & 6 & 56 & 30 & 115 & 33 \\
\hline & & Efluente & 6 & 58 & 10 & 116 & 45 \\
\hline
\end{tabular}

Tabela 6 - Estatísticas descritivas da fase operacional 03 (Linha 01)

\begin{tabular}{|c|c|c|c|c|c|c|c|}
\hline Fase & Parâmetro & Amostra & $\begin{array}{c}\text { No } \\
\text { Dados }\end{array}$ & $\begin{array}{l}\text { Média } \\
(\mathrm{mg} / \mathrm{L})\end{array}$ & $\begin{array}{c}\text { Mínimo } \\
(\mathrm{mg} / \mathrm{L})\end{array}$ & $\begin{array}{c}\text { Máximo } \\
(\mathrm{mg} / \mathrm{L})\end{array}$ & $\begin{array}{l}\text { Desvio } \\
\text { Padráo }\end{array}$ \\
\hline \multirow{12}{*}{3} & \multirow{4}{*}{ DQO } & Esgoto bruto & 15 & 224 & 90 & 462 & 102 \\
\hline & & Lixiviado bruto & 16 & 1989 & 1530 & 2802 & 397 \\
\hline & & Diluição (afluente) & 14 & 238 & 143 & 597 & 113 \\
\hline & & Efluente & 15 & 119 & 35 & 228 & 56 \\
\hline & \multirow{4}{*}{$\mathrm{DBO}$} & Esgoto bruto & 13 & 118 & 61 & 183 & 36 \\
\hline & & Lixiviado bruto & 2 & 245 & 198 & 292 & 66 \\
\hline & & Diluição (afluente) & 10 & 142 & 97 & 243 & 55 \\
\hline & & Efluente & 12 & 42 & 17 & 85 & 21 \\
\hline & \multirow{4}{*}{$\mathrm{N}$-amoniacal } & Esgoto bruto & 8 & 32 & 10 & 49 & 12 \\
\hline & & Lixiviado bruto & 6 & 564 & 76 & 700 & 242 \\
\hline & & Diluição (afluente) & 7 & 46 & 11 & 119 & 34 \\
\hline & & Efluente & 7 & 22 & 13 & 32 & 7 \\
\hline
\end{tabular}


Tabela 7 - Estatísticas descritivas da fase operacional 04 (Linha 01)

\begin{tabular}{|c|c|c|c|c|c|c|c|}
\hline Fase & Parâmetro & Amostra & $\begin{array}{c}\text { No } \\
\text { Dados }\end{array}$ & $\begin{array}{l}\text { Média } \\
(\mathrm{mg} / \mathrm{L})\end{array}$ & $\begin{array}{c}\text { Mínimo } \\
(\mathrm{mg} / \mathrm{L})\end{array}$ & $\begin{array}{c}\text { Máximo } \\
(\mathrm{mg} / \mathrm{L})\end{array}$ & $\begin{array}{l}\text { Desvio } \\
\text { Padrão }\end{array}$ \\
\hline \multirow{12}{*}{4} & \multirow{4}{*}{ DQO } & Esgoto bruto & 10 & 272 & 133 & 569 & 143 \\
\hline & & Lixiviado bruto & 8 & 2559 & 2289 & 2910 & 249 \\
\hline & & Diluição (afluente) & 8 & 248 & 108 & 377 & 79 \\
\hline & & Efluente & 9 & 132 & 41 & 201 & 50 \\
\hline & \multirow{4}{*}{$\mathrm{DBO}$} & Esgoto bruto & 9 & 148 & 58 & 231 & 52 \\
\hline & & Lixiviado bruto & - & - & - & - & - \\
\hline & & Diluição (afluente) & 8 & 137 & 57 & 201 & 43 \\
\hline & & Efluente & 9 & 51 & 10 & 94 & 23 \\
\hline & \multirow{4}{*}{$\mathrm{N}$-amoniacal } & Esgoto bruto & 10 & 36 & 30 & 42 & 5 \\
\hline & & Lixiviado bruto & 8 & 1311 & 764 & 2032 & 414 \\
\hline & & Diluição (afluente) & 8 & 37 & 9 & 48 & 12 \\
\hline & & Efluente & 9 & 29 & 23 & 38 & 5 \\
\hline
\end{tabular}

Tabela 8 - Estatísticas descritivas da fase operacional 05 (Linha 01)

\begin{tabular}{|c|c|c|c|c|c|c|c|}
\hline Fase & Parâmetro & Amostra & $\begin{array}{c}\text { No } \\
\text { Dados }\end{array}$ & $\begin{array}{l}\text { Média } \\
(\mathrm{mg} / \mathrm{L})\end{array}$ & $\begin{array}{c}\text { Mínimo } \\
(\mathrm{mg} / \mathrm{L})\end{array}$ & $\begin{array}{c}\text { Máximo } \\
(\mathrm{mg} / \mathrm{L})\end{array}$ & $\begin{array}{l}\text { Desvio } \\
\text { Padrăo }\end{array}$ \\
\hline \multirow{12}{*}{5} & \multirow{4}{*}{ DQO } & Esgoto bruto & 5 & 175 & 145 & 220 & 29 \\
\hline & & Lixiviado bruto & 5 & 2421 & 927 & 3635 & 1136 \\
\hline & & Diluição (afluente) & 7 & 296 & 108 & 994 & 316 \\
\hline & & Efluente & 7 & 258 & 77 & 859 & 275 \\
\hline & \multirow{4}{*}{$\mathrm{DBO}$} & Esgoto bruto & 4 & 89 & 75 & 108 & 14 \\
\hline & & Lixiviado bruto & - & - & - & - & - \\
\hline & & Diluição (afluente) & 6 & 138 & 62 & 400 & 129 \\
\hline & & Efluente & 6 & 72 & 30 & 140 & 41 \\
\hline & \multirow{4}{*}{$\mathrm{N}$-amoniacal } & Esgoto bruto & 5 & 35 & 19 & 50 & 12 \\
\hline & & Lixiviado bruto & 5 & 1136 & 935 & 1317 & 148 \\
\hline & & Diluição (afluente) & 7 & 37 & 15 & 58 & 15 \\
\hline & & Efluente & 7 & 24 & 18 & 39 & 7 \\
\hline
\end{tabular}

Tabela 9 - Estatísticas descritivas da fase operacional 01 (Linha 02)

\begin{tabular}{|c|c|c|c|c|c|c|c|}
\hline Fase & Parâmetro & Amostra & $\begin{array}{c}\text { No }^{\circ} \\
\text { Dados }\end{array}$ & $\begin{array}{l}\text { Média } \\
(\mathrm{mg} / \mathrm{L})\end{array}$ & $\begin{array}{c}\text { Mínimo } \\
(\mathrm{mg} / \mathrm{L})\end{array}$ & $\begin{array}{c}\text { Máximo } \\
(\mathrm{mg} / \mathrm{L})\end{array}$ & $\begin{array}{l}\text { Desvio } \\
\text { Padrão }\end{array}$ \\
\hline \multirow{12}{*}{1} & \multirow{4}{*}{ DQO } & Esgoto bruto & 15 & 490 & 115 & 1728 & 447 \\
\hline & & Lixiviado bruto & 15 & 1943 & 1536 & 2592 & 337 \\
\hline & & Diluição (afluente) & 13 & 258 & 134 & 422 & 83 \\
\hline & & Efluente & 13 & 110 & 42 & 197 & 46 \\
\hline & \multirow{4}{*}{$\mathrm{DBO}$} & Esgoto bruto & 15 & 238 & 37 & 654 & 176 \\
\hline & & Lixiviado bruto & 15 & 382 & 118 & 2491 & 590 \\
\hline & & Diluição (afluente) & 13 & 165 & 43 & 294 & 71 \\
\hline & & Efluente & 11 & 49 & 16 & 78 & 20 \\
\hline & \multirow{4}{*}{$\mathrm{N}$-amoniacal } & Esgoto bruto & 7 & 47 & 17 & 126 & 36 \\
\hline & & Lixiviado bruto & 7 & 2056 & 533 & 2630 & 724 \\
\hline & & Diluição (afluente) & 7 & 115 & 39 & 232 & 72 \\
\hline & & Efluente & 7 & 15 & 9 & 25 & 6 \\
\hline
\end{tabular}


Tabela 10 - Estatísticas descritivas da fase operacional 02 (Linha 02)

\begin{tabular}{|c|c|c|c|c|c|c|c|}
\hline Fase & Parâmetro & Amostra & $\begin{array}{c}\text { No } \\
\text { Dados }\end{array}$ & $\begin{array}{l}\text { Média } \\
(\mathrm{mg} / \mathrm{L})\end{array}$ & $\begin{array}{c}\text { Mínimo } \\
(\mathrm{mg} / \mathrm{L})\end{array}$ & $\begin{array}{c}\text { Máximo } \\
(\mathrm{mg} / \mathrm{L})\end{array}$ & $\begin{array}{l}\text { Desvio } \\
\text { Padráo }\end{array}$ \\
\hline \multirow{12}{*}{2} & \multirow{4}{*}{$\mathrm{DQO}$} & Esgoto bruto & 13 & 266 & 107 & 566 & 124 \\
\hline & & Lixiviado bruto & 13 & 1578 & 672 & 2080 & 407 \\
\hline & & Diluiçáo (afluente) & 12 & 337 & 105 & 900 & 231 \\
\hline & & Efluente & 12 & 84 & 28 & 192 & 47 \\
\hline & \multirow{4}{*}{$\mathrm{DBO}$} & Esgoto bruto & 11 & 141 & 84 & 237 & 40 \\
\hline & & Lixiviado bruto & 11 & 211 & 112 & 348 & 85 \\
\hline & & Diluição (afluente) & 10 & 170 & 71 & 406 & 106 \\
\hline & & Efluente & 9 & 32 & 11 & 80 & 22 \\
\hline & \multirow{4}{*}{ N-amoniacal } & Esgoto bruto & 5 & 51 & 17 & 98 & 32 \\
\hline & & Lixiviado bruto & 5 & 913 & 275 & 2440 & 869 \\
\hline & & Diluição (afluente) & 5 & 66 & 21 & 104 & 37 \\
\hline & & Efluente & 5 & 28 & 9 & 47 & 15 \\
\hline
\end{tabular}

Tabela 11 - Estatísticas descritivas da fase operacional 03 (Linha 02)

\begin{tabular}{|c|c|c|c|c|c|c|c|}
\hline Fase & Parâmetro & Amostra & $\begin{array}{c}\text { No } \\
\text { Dados }\end{array}$ & $\begin{array}{l}\text { Média } \\
(\mathrm{mg} / \mathrm{L})\end{array}$ & $\begin{array}{c}\text { Mínimo } \\
(\mathrm{mg} / \mathrm{L})\end{array}$ & $\begin{array}{c}\text { Máximo } \\
(\mathrm{mg} / \mathrm{L})\end{array}$ & $\begin{array}{l}\text { Desvio } \\
\text { Padráo }\end{array}$ \\
\hline \multirow{12}{*}{3} & \multirow{4}{*}{$\mathrm{DQO}$} & Esgoto bruto & 14 & 215 & 53 & 427 & 110 \\
\hline & & Lixiviado bruto & 16 & 1480 & 1080 & 2110 & 316 \\
\hline & & Diluição (afluente) & 15 & 275 & 93 & 872 & 193 \\
\hline & & Efluente & 15 & 92 & 9 & 324 & 75 \\
\hline & \multirow{4}{*}{$\mathrm{DBO}$} & Esgoto bruto & 11 & 118 & 58 & 169 & 33 \\
\hline & & Lixiviado bruto & 2 & 189 & 174 & 204 & 21 \\
\hline & & Diluição (afluente) & 13 & 165 & 66 & 454 & 99 \\
\hline & & Efluente & 12 & 27 & 5 & 49 & 14 \\
\hline & \multirow{4}{*}{ N-amoniacal } & Esgoto bruto & 10 & 31 & 8 & 47 & 10 \\
\hline & & Lixiviado bruto & 6 & 739 & 68 & 977 & 350 \\
\hline & & Diluição (afluente) & 8 & 35 & 10 & 55 & 13 \\
\hline & & Efluente & 6 & 17 & 3 & 37 & 12 \\
\hline
\end{tabular}

Tabela 12 - Estatísticas descritivas da fase operacional 04 (Linha 02)

\begin{tabular}{|c|c|c|c|c|c|c|c|}
\hline Fase & Parâmetro & Amostra & $\begin{array}{c}\text { No } \\
\text { Dados }\end{array}$ & $\begin{array}{l}\text { Média } \\
(\mathrm{mg} / \mathrm{L})\end{array}$ & $\begin{array}{c}\text { Mínimo } \\
(\mathrm{mg} / \mathrm{L})\end{array}$ & $\begin{array}{c}\text { Máximo } \\
(\mathrm{mg} / \mathrm{L})\end{array}$ & $\begin{array}{l}\text { Desvio } \\
\text { Padráo }\end{array}$ \\
\hline \multirow{12}{*}{4} & \multirow{4}{*}{$\mathrm{DQO}$} & Esgoto bruto & 9 & 226 & 117 & 421 & 95 \\
\hline & & Lixiviado bruto & 9 & 1921 & 1235 & 3340 & 654 \\
\hline & & Diluiçáo (afluente) & 11 & 222 & 117 & 389 & 82 \\
\hline & & Efluente & 11 & 72 & 33 & 173 & 40 \\
\hline & \multirow{4}{*}{$\mathrm{DBO}$} & Esgoto bruto & 10 & 131 & 74 & 185 & 32 \\
\hline & & Lixiviado bruto & - & - & - & - & - \\
\hline & & Diluiçāo (afluente) & 10 & 135 & 70 & 234 & 45 \\
\hline & & Efluente & 9 & 33 & 10 & 74 & 20 \\
\hline & \multirow{4}{*}{$\mathrm{N}$-amoniacal } & Esgoto bruto & 10 & 35 & 29 & 48 & 7 \\
\hline & & Lixiviado bruto & 10 & 1141 & 624 & 1949 & 375 \\
\hline & & Diluição (afluente) & 11 & 42 & 9 & 105 & 24 \\
\hline & & Efluente & 11 & 13 & 1 & 38 & 17 \\
\hline
\end{tabular}


Tabela 13 - Estatísticas descritivas da fase operacional 05 (Linha 02)

\begin{tabular}{|c|c|c|c|c|c|c|c|}
\hline Fase & Parâmetro & Amostra & $\begin{array}{c}\text { No } \\
\text { Dados }\end{array}$ & $\begin{array}{l}\text { Média } \\
(\mathrm{mg} / \mathrm{L})\end{array}$ & $\begin{array}{c}\text { Mínimo } \\
(\mathrm{mg} / \mathrm{L})\end{array}$ & $\begin{array}{c}\text { Máximo } \\
(\mathrm{mg} / \mathrm{L})\end{array}$ & $\begin{array}{l}\text { Desvio } \\
\text { Padráo }\end{array}$ \\
\hline \multirow{12}{*}{5} & \multirow{4}{*}{ DQO } & Esgoto bruto & 4 & 216 & 129 & 465 & 166 \\
\hline & & Lixiviado bruto & 4 & 1833 & 1495 & 2350 & 415 \\
\hline & & Diluiçáo (afluente) & 6 & 295 & 126 & 831 & 268 \\
\hline & & Efluente & 6 & 90 & 37 & 189 & 54 \\
\hline & \multirow{4}{*}{$\mathrm{DBO}$} & Esgoto bruto & 4 & 102 & 74 & 166 & 44 \\
\hline & & Lixiviado bruto & - & - & - & - & - \\
\hline & & Diluição (afluente) & 6 & 127 & 74 & 233 & 59 \\
\hline & & Efluente & 5 & 33 & 21 & 45 & 11 \\
\hline & \multirow{4}{*}{$\mathrm{N}$-amoniacal } & Esgoto bruto & 4 & 33 & 18 & 51 & 14 \\
\hline & & Lixiviado bruto & 4 & 1035 & 903 & 1267 & 169 \\
\hline & & Diluição (afluente) & 6 & 40 & 20 & 56 & 15 \\
\hline & & Efluente & 6 & 10 & 3 & 24 & 7 \\
\hline
\end{tabular}

Para facilitar o entendimento, na Tabela 14 estáo apresentados os dados resumidos de desempenho das linhas 01 e 02 para todas as fases operacionais da pesquisa.

Tabela 14 - Resumo do desempenho da Linha de tratamento 01 e 02

\begin{tabular}{|c|c|c|c|c|c|c|c|}
\hline \multirow{2}{*}{} & \multicolumn{2}{c|}{ Fase } & \multicolumn{2}{c|}{ DQO } & \multicolumn{2}{c|}{ DBO } & \multicolumn{2}{c|}{ N-amoniacal } \\
\cline { 3 - 8 } & Linha1 & Linha2 & Linha1 & Linha2 & Linha1 & Linha2 \\
\hline \multirow{3}{*}{01} & Efluente (mg/L) & 173 & 110 & 75 & 49 & 50 & 15 \\
\cline { 2 - 8 } & Eficiência (\%) & 44 & 56 & 54 & 65 & 53 & 84 \\
\hline \multirow{2}{*}{02} & Efluente (mg/L) & 141 & 84 & 58 & 32 & 58 & 28 \\
\cline { 2 - 8 } & Eficiência (\%) & 41 & 66 & 51 & 78 & 37 & 51 \\
\hline \multirow{2}{*}{03} & Efluente (m/L) & 119 & 92 & 42 & 27 & 22 & 17 \\
\cline { 2 - 8 } & Eficiência (\%) & 47 & 62 & 71 & 78 & 49 & 60 \\
\hline \multirow{3}{*}{04} & Efluente (mg/L) & 132 & 72 & 51 & 33 & 29 & 13 \\
\cline { 2 - 8 } & Eficiência (\%) & 42 & 62 & 59 & 71 & 32 & 75 \\
\hline \multirow{2}{*}{05} & Efluente (mg/L) & 258 & 90 & 72 & 33 & 24 & 10 \\
\cline { 2 - 8 } & Eficiência (\%) & 57 & 68 & 53 & 71 & 36 & 77 \\
\hline \multirow{2}{*}{ Esgoto* } & Efluente (mg/L) & 130 & 72 & 45 & 27 & - & - \\
\cline { 2 - 8 } & Eficiência (\%) & 71 & 82 & 70 & 81 & - & - \\
\hline
\end{tabular}

Obs.: * - desempenho das linhas 01 e 02 tratando somente esgoto doméstico durante 02 anos de operaçâo

FONSECA, 2005 e MATOS, 2005 (náo houve análise de $\mathrm{N}$-amoniacal neste período)

Nos gráficos das Figuras 2 e 3, pode-se observar, respectivamente para eficiência de remoçáo e concentração efluente, a comparaçáo entre resultados somente das fases que apresentaram melhores desempenhos das linhas de tratamento 01 e 02 , para os parâmetros DQO, DBO e nitrogênio amoniacal. 


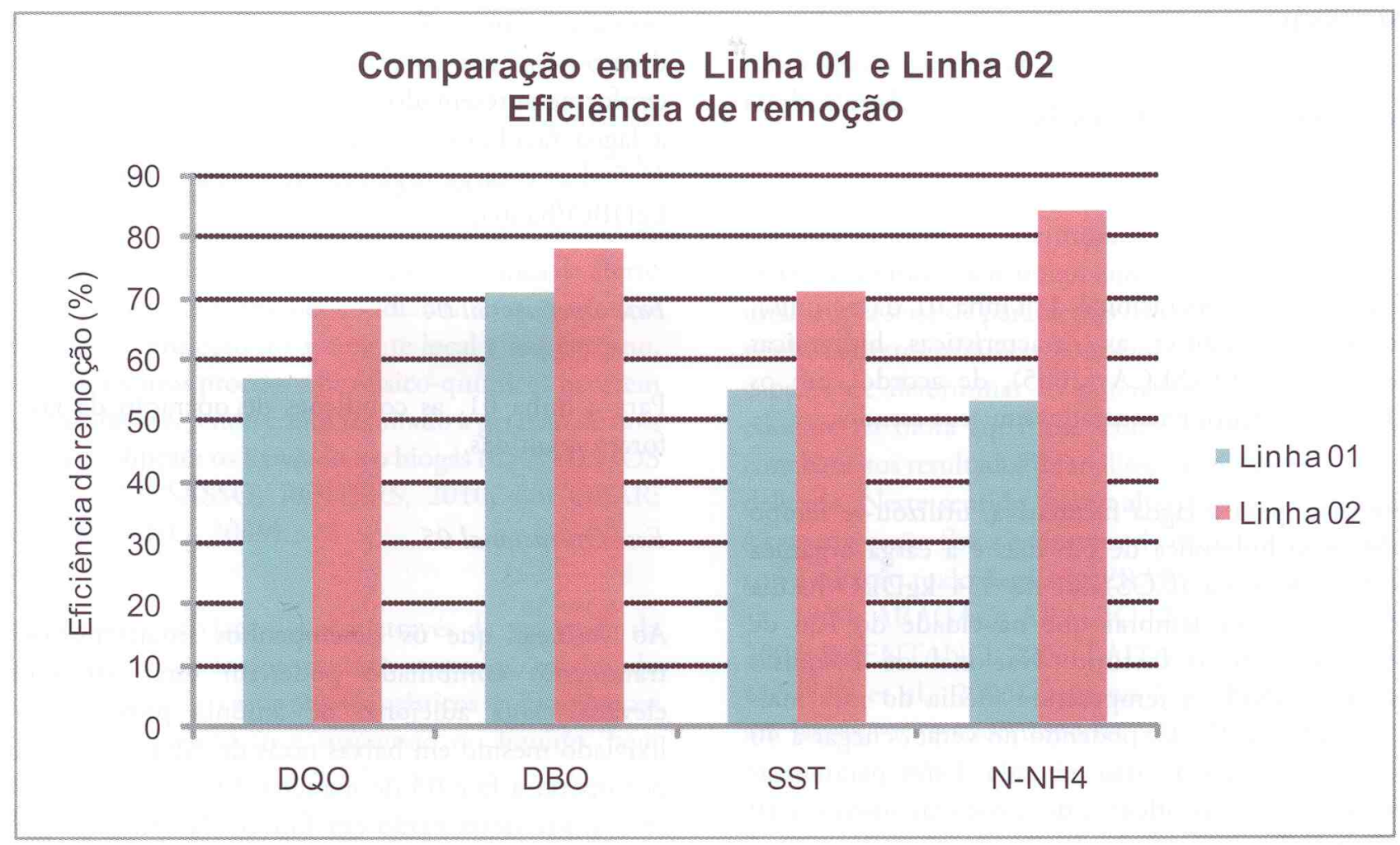

Figura 2 - Comparação entre eficiências de remoçáo da Linha 01 e da Linha 02

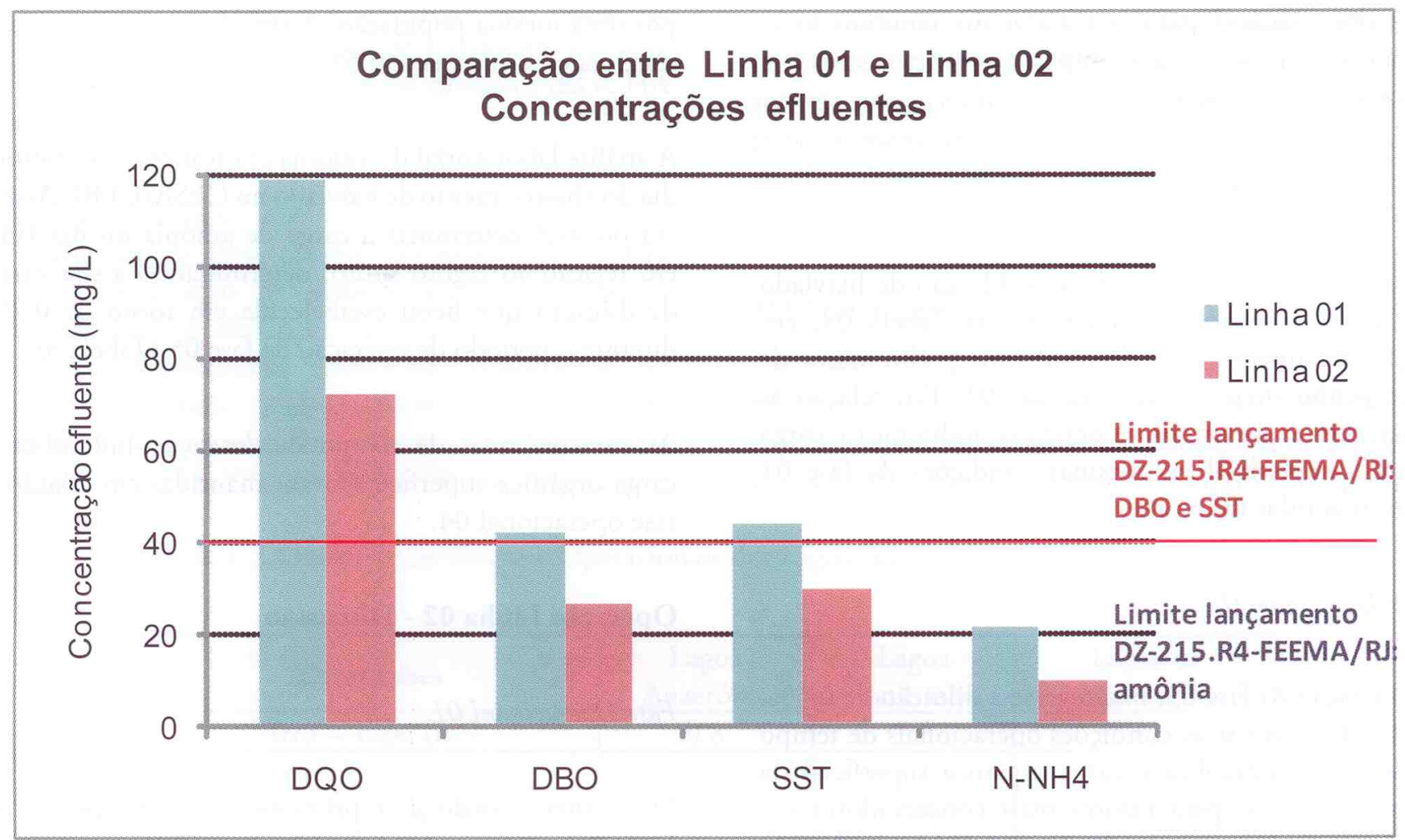

Figura 3 - Comparaçấo entre concentraçốes efluentes da Linha 01 e da Linha 02 


\section{DISCUSSÃO}

\section{Operaçáo Linha 01 - Discussáo}

\section{Fase Operacional 01}

Na primeira fase operacional da Linha 01 da pesquisa, optou-se por manter as características hidráulicas sugeridas por FONSECA (2005), de acordo com os melhores resultados encontrados em seus estudos.

Neste caso, para a lagoa facultativa, utilizou-se tempo de detenção hidráulica de 6,6 dias e a carga orgânica superficial adotada (COS) foi de $334 \mathrm{kgDBO} /$ ha.dia (Tabela 01). Vale lembrar que na cidade do Rio de Janeiro, segundo o Instituto Nacional de Pesquisas Espaciais - INPE, a temperatura média do mês mais frio (julho) é de $17^{\circ} \mathrm{C}$, podendo no verão, chegar a 40 ${ }^{\circ} \mathrm{C}$, o que justifica a carga adotada. Estes parâmetros definiram uma vazáo afluente de aproximadamente 0,10 $\mathrm{L} / \mathrm{s}$ (Tabela 3).

Para a diluiçấo do lixiviado, optou-se por iniciar com $2 \%$ de vazáo de lixiviado em relaçáo à vazấo de esgoto doméstico afluente ao sistema, acreditando-se ser este um valor razoável para o tratamento combinado e, portanto que causaria baixo impacto ao sistema existente de tratamento de esgoto.

\section{Fase Operacional 02}

Nesta fase, optou-se por reduzir a diluição de lixiviado para $0,5 \%$, conforme apresentado na Tabela 03 , em funçáo da apresentaçáo de resultados preliminares de desempenho insatisfatórios na fase 01 . Em relaçấo ás características de tempo de detenção hidráulica e carga orgânica superficial, as mesmas condiçóes da fase 01 foram mantidas (Tabela 1).

\section{Fase Operacional 03}

Na operaçáo da fase 03 , manteve-se a diluição de $0,5 \%$, porém alteraram-se as condiçốes operacionais de tempo de detenção hidráulica e carga orgânica superficial da lagoa facultativa, para valores mais conservadores em relação ao tratamento de esgoto doméstico. JORDÃO e PESSOA (2009) sugerem para essas lagoas, tempo de detenção variando entre 15 e 45 dias e taxa de aplicaçáo superficial entre 100 e $350 \mathrm{kgDBO} /$ ha.dia para regiôes tropicais com sol e temperatura uniformemente distribuídos, sem coberturas de nuvens sazonais. Assim, conforme apresentado na Tabela 1, determinou-se para a lagoa facultativa, tempo de detenção hidráulica de 16,5 dias e carga orgânica superficial adotada de 134 $\mathrm{kgDBO} /$ ha.dia.

\section{Fase Operacional 04}

Para a linha 01, as condições de operação da fase 03 foram mantidas.

\section{Fase Operacional 05}

Ao verificar que os desempenhos insatisfatórios do tratamento combinado poderiam estar atrelados à elevada carga adicional de amônia proveniente do lixiviado mesmo em baixas taxas de diluiçóes, optou-se por operar a fase 05 de maneira diferenciada, fazendose o ajuste desta vazão em função da concentração de amônia detectada no lixiviado, cuja freqüência de abastecimento era semanal. Dessa forma, optou-se por adotar uma vazáo de lixiviado que produzisse uma baixa carga de amônia em relaçáo à de esgoto e ainda permitisse o tratamento de todo o lixiviado produzido por uma mesma populaçáo. Assim, fixou-se essa relação máxima entre cargas, em 5\%.

A análise laboratorial de amônia era realizada no mesmo dia do abastecimento de lixiviado no CESA/UFRJ. Assim era possível determinar a carga de amônia do lixiviado em relaçấo ao esgoto bruto, determinando a sua vazão de diluiçáo que ficou estabelecida em torno de 0,2\% durante o período de operaçáo da fase 05 (Tabela 3).

As características de tempo de detenção hidráulica e carga orgânica superficial foram mantidas em relaçáo à fase operacional 04 .

\section{Operaçáo Linha 02 - Discussão}

\section{Fase Operacional 01}

De maneira análoga à primeira fase operacional da Linha 01, no caso da Linha 02, optou-se por manter as características hidráulicas sugeridas por MATOS (2005), de acordo com os melhores resultados encontrados em seus estudos. 
Neste caso, para a lagoa aerada, utilizou-se tempo de detençấo hidráulica de 4,8 dias, resultando em uma vazáo de $0,15 \mathrm{~L} / \mathrm{s}$, conforme apresentado na Tabela 02. Assim como na fase inicial da Linha 01 , na Linha 02 também se iniciou a pesquisa com uma diluiçáo de $2 \%$ de vazâo de lixiviado em relaçáo à vazâo de esgoto doméstico afluente ao sistema (Tabela 3)

\section{Fase Operacional 02}

Em função de desempenho insatisfatório na primeira fase da pesquisa, reduziu-se a diluiçáo para $0,5 \%$, mas mantiveram-se as condiçôes de carga orgânica superficial e tempo de detençáo hidráulica (Tabelas 2 e 3 ).

\section{Fase Operacional 03}

$\mathrm{Na}$ operação da fase 03 , manteve-se a diluição de $0,5 \%$, porém alteraram-se as condiçôes operacionais de tempo de detenção hidráulica e carga orgânica superficial da lagoa aerada, para valores mais conservadores em relação ao tratamento de esgoto doméstico. Definiu-se assim, de acordo com a Tabela 2, o tempo de detençáo hidráulica de 3,6 dias; segundo JORDĀO e PESSOA (2009) valores usuais de conforto estão situados entre 2 e 10 dias.

\section{Fase Operacional 04}

Nesta fase, manteve-se a diluiçắo de lixiviado de $0,5 \%$, porém aumentou-se o tempo de detençấo hidráulica para 7,1 dias, como pode ser observado na Tabela 2 , aproximando-o de valores mais conservadores recomendados pela literatura.

\section{Fase Operacional 05}

A mesma discussão da fase operacional 05 da Linha 01 aplica-se para esta, em relaçấo à adoçáo do ajuste de vazáo em funçấo da concentraçáo de amônia detectada no lixiviado, fixando-se a relaçăo máxima entre cargas de amônia de lixiviado e de esgoto, em 5\%.

Assim, a vazão de diluição ficou estabelecida em torno de 0,2\% durante o período de operação da fase 05 (Tabela 3).

\section{Avaliaçáo de Desempenho da Linha 01 - Discussáo}

A linha de tratamento 01 apresentou resultados insatisfatórios quando comparados à sua operaçáo tratando somente esgoto doméstico e quando comparados á operaçáo da linha de tratamento 02 .

Para a linha 01 , a fase operacional 01 , com diluição de $2 \%$ apresentou o pior desempenho, com eficiência média de remoção de DQO e DBO de $44 \%$ e $54 \%$, respectivamente. Ainda o efluente dessa fase operacional apresentou concentração média efluente de nitrogênio amoniacal de $50 \mathrm{mg} / \mathrm{L}$, valor bastante elevado, podendo comprometer a qualidade do corpo d'água receptor.

Ainda para a linha 01, a fase operacional 03, com diluiçáo de $0,5 \%$, tempo de detençáo hidráulica de 16,5 dias e carga orgânica superficial adotada de 134 $\mathrm{kgDBO} /$ ha.dia (valores mais conservadores) apresentou o melhor resultado em relaçáo ao parâmetro DBO ( $71 \%$ de eficiência de remoçáo), comparado à operação do sistema com esgoto sanitário $(70 \%$ de eficiência de remoçáo). Seu efluente inclusive, apresentou concentraçáo média do mesmo parâmetro $=42 \mathrm{mg} / \mathrm{L}$, próximo ao índice limite $(40 \mathrm{mg} / \mathrm{L})$ da faixa mais restritiva da legislaçáo estadual do Rio de Janeiro para lançamento de efluentes em corpos d'água (DZ-215. R4 FEEMA, 2007). Ainda nesta fase, a concentraçáo média efluente de nitrogênio amoniacal foi de $22 \mathrm{mg} / \mathrm{L}$, próximo ao valor limite anteriormente determinado pela legislação federal, Resoluçấo CONAMA nº 357, para lançamento em corpos d'água. Nesta fase, a adiçấo de $0,5 \%$ de lixiviado representou um aumento de aproximadamente $12 \%$ de carga de amônia no afluente. Cabe ressaltar, que atualmente a mesma legislaçáo, não mais impóe este limite, por entender a dificuldade de se alcançar este valor em tratamentos convencionais de esgoto doméstico no Brasil.

\section{Avaliaçáo de Desempenho da Linha 02 - Discussáo}

Já para a linha operacional 02 , com exceção da fase 01 , que teve diluiçáo elevada de $2 \%$ de volume de lixiviado em relaçáo ao volume de esgoto, todas as outras fases apresentaram desempenho satisfatório quanto ao parâmetro $\mathrm{DBO}$, quando comparadas à operação da linha tratando somente esgoto doméstico. As fases 02, 03, 04 e 05 ainda apresentaram concentração média efluente de $\mathrm{DBO}$ menor do que $40 \mathrm{mg} / \mathrm{L}$, valor limite para lançamento em corpos d'água da faixa mais restritiva da legislaçấo estadual do Rio de Janeiro (DZ215.R4, FEEMA)

O desempenho das unidades para o parâmetro DQO 
também se mostrou satisfatório na linha 02 , apesar das eficiências médias de remoção estarem entre $62 \%$ e $68 \%$ nas fases 02 a 05 , apresentando concentração média efluente entre $72 \mathrm{mg} / \mathrm{L}$ e $92 \mathrm{mg} / \mathrm{L}$.

A remoção de amônia nesta, também foi satisfatória, apresentando efluentes com concentração média de nitrogênio amoniacal variando de $10 \mathrm{mg} / \mathrm{L}$ a $28 \mathrm{mg} / \mathrm{L}$, até mesmo na fase 01 , onde a diluição de $2 \%$ representou um aumento de $87 \%$ de carga de amônia no afluente.

\section{CONCLUSỐES}

- A lagoa facultativa pode náo ser uma boa opçáo para o tratamento combinado, por ser um processo extremamente natural e, portanto mais susceptível tanto a variaçóes de carga de DQO, DBO e amônia, como à toxicidade imposta pela elevada concentraçáo de amônia presente nos lixiviados. $\mathrm{Na}$ pesquisa, resultados satisfatórios para a lagoa facultativa (linha 01) somente foram alcançados na fase 03 , com diluiçáo de $0,5 \%(\mathrm{v} / \mathrm{v})$, quando as unidades apresentaram eficiência média de remoçáo de DBO de $71 \%$ e concentração média efluente de $42 \mathrm{mg} / \mathrm{L}$.

- Já a lagoa aerada se apresentou menos vulnerável em relação à variaçáo de carga afluente, imposta pela diluiçáa de lixiviado, além de apresentar boa capacidade de remoção de amônia, por volatilizaçáo. Assim, o sistema que compóe a lagoa aerada (linha 02) se configura como uma tecnologia viável para o tratamento combinado com até $0,5 \%$ de diluição $(\mathrm{v} / \mathrm{v})$. Nestes casos, as unidades apresentaram concentração efluente de DBO menor que $40 \mathrm{mg} / \mathrm{L}$ e de DQO menor que $100 \mathrm{mg} / \mathrm{L}$, além de uma boa remoção de amônia, com concentraçáo média efluente de $28 \mathrm{mg} / \mathrm{L}$ no pior caso (fase 02 ) e de 10 $\mathrm{mg} / \mathrm{L}$ na fase de melhor desempenho operacional (fase 05).

- Os resultados demonstram maior fragilidade da lagoa facultativa em receber adiçấo de carga de DQO, DBO e principalmente amônia, em função da adiçấo do lixiviado. Acredita-se que o maior crédito para o baixo desempenho da lagoa facultativa deve ser dado à adiçấo de carga de amônia. Dessa maneira, sugere-se a realização da volatilização de amônia do lixiviado bruto, anteriormente à sua diluiçáo para tratamento. Ressalta-se que em nenhuma etapa da pesquisa, o parâmetro de lançamento de
$\mathrm{N}$-amoniacal determinado pela legislaçáo do Rio de Janeiro foi alcançado.

- Sugere-se que para a realização do tratamento combinado, adote-se um índice de diluiçáo em funçáo do aumento da carga orgânica e/ou de amônia por ocasiáo da adiçáo do lixiviado e nấo do volume, como tem sido feito normalmente. Os lixiviados de diferentes aterros são muitos distintos e, portanto diluiçôes em função somente da vazáo podem acarretar impactos na ETE, bastante discrepantes.

\section{REFERÊNCIAS}

ASSOCIAÇÃO BRASILEIRA DE EMPRESAS DE LIMPEZA PÚBLICA E RESÍDUOS ESPECIAIS (ABRELPE). Panorama dos Resíduos Sólidos no Brasil, 2010. 199p.

AWWA/APHA/WEF. Standard Methods for the Examination of Water and Wastewater. $20^{\text {th }}$ ed., New York; USA, 1998.

SNIS - SISTEMA NACIONAL DE INFORMAÇÔES SOBRE SANEAMENTO. Diagnóstico do Manejo de Resíduos Sólidos Urbanos - 2008. Ministério das Cidades. Parte 01 - Texto-Visão Geral da Prestação de Serviços, 264p. Brasília, 2010.

FLECK, E. Sistema Integrado por Filtro Anaeróbio, Filtro Biológico de Baixa Taxa e Banhado Construido Aplicado ao Tratamento de Lixiviado de Aterro Sanitário. Dissertaçáo de Mestrado. Instituto de Pesquisas Hidráulicas da Universidade Federal do Rio Grande do Sul - IPH/ UFRGS, 2003.

FONSECA, P.W. Avaliaçāo do Desempenho $e$ Caracterização de Parâmetros em Lagoas Facultativa e de Maturação: Dissertação de Mestrado. Programa de PósGraduação em Engenharia da Universidade Federal do Rio de Janeiro - COPPE/UFRJ, 2005.

GIUSTI, L. A Review of Waste Management Practices and Their Impacts of Human Health. Waste Management, 29: 2227-2239, 2009.

GOMES, L.P. (coordenadora). Estudos de Caracterizaçâao e Tratabilidade de Lixiviados de Aterros Sanitários para as 
Condiçōes Brasileiras. PROSAB - tema III edital V. Rio de Janeiro, 2009 - 360p.

HARADA, T., TANIZAWA, F., TAUE, S., NISHIMURA, Y., OSHIKATA, T., FURUICHI, T. e HANASHIMA, M. Changes in Subsurface Linear Systems and Leachate Treatment Technologies for Final Disposal Sites in Japan. In: XI International Waste Management and Landfill Symposium. Sardinia, Italy - 2007.

JORDÁO, E.P e PESSOA, C.A. Tratamento de Esgotos Domésticos. 5a Ediçấo. ABES, Rio de Janeiro, 940 p. 2009.

MATOS, O. S. Avaliação do Desempenho e Caracterizaçāo de Parâmetros em Lagoa Aerada Seguida de Lagoa de Sedimentação. Dissertaçáo de Mestrado. Programa de Pós-Graduaçáo em Engenharia da Universidade Federal do Rio de Janeiro - COPPE/UFRJ, 2005.

PENIDO J.H.M. Transformando um Passivo Ambiental em Recurso Energético: El Metano como Fuente de Energia $y$ de Recursos. In: III Congreso Interamericano de Residuos - AIDIS. Buenos Aires, 2009.

PERSSON, K.M., VAN PRAAGH, M. e OLSBERG, E. Removal of Heavy Metals from Landfill Leachate by an Artificial Wetland During a Nordic Autum. In: XI International Waste Management and Landfill Symposium. Sardinia, Italy - 2007.

POVINELLI, J. e SOUTO, G.D.B. Ammonia Stripping from Landfill Leachate Using Packed Towers.
In: XII International Waste Management and Landfill Symposium. Sardinia, Italy - 2009.

ReCESA - Rede Nacional de Extensão e Capacitação Tecnológica em Saneamento Ambiental. Resíduos Sólidos: Projeto, Operação e Monitoramento de Aterros Sanitários: Guia do Profissional em Treinamento - nivel 2. Ministério das Cidades. Secretaria Nacional de Saneamento Ambiental. 120p. Belo Horizonte, 2008.

RIO DE JANEIRO. Fundação Estadual de Engenharia do Meio Ambiente. DZ-215-R4/setembro de 2007. Diretriz de Controle de Carga Orgânica Biodegradável em Efuentes Liquidos de Origem Sanitária. Rio de Janeiro, 25 de setembro de 2007.

SANTOS, A.S.P. Aspectos Técnicos e Econômicos do Tratamento Combinado de Lixiviado de Aterro Sanitário com Esgoto Doméstico em Lagoas de Estabilização. Tese de Doutorado. Programa de Pós-Graduação em Engenharia da Universidade Federal do Rio de Janeiro - COPPE/ UFRJ, 2010

SCHARFF, H., KOK, B. e KROM, A.H. The Role of Sustainable Landfill in Future Waste Management Systems. In: XI International Waste Management and Landfill Symposium. Sardinia, Italy - 2007.

THORNELOE, S.A. U.S. EPA's Research to Update Guidance for Quantifying Landfill Gas Emissions. In: XI International Waste Management and Landfill Symposium. Sardinia, Italy - 2007. 